\title{
Relationships between the upper central incisor crown forms and degree of labial inclination, overbite, and overjet in Japanese young adults
}

\author{
Takeshi Kurita ${ }^{1 *}$, Fumi Mizuhashi², ${ }^{\text {Toshihide Sato }}{ }^{3}$, Kaoru Koide ${ }^{2}$ \\ ${ }^{1}$ Functional Occlusal Treatment, The Nippon Dental University Graduate School of Life Dentistry at Niigata, Japan \\ 2Department of Removable Prosthodontics, The Nippon Dental University School of Life Dentistry at Niigata, Japan \\ ${ }^{3}$ Museum of Medicine and Dentistry, The Nippon Dental University School of Life Dentistry, Japan
}

\begin{abstract}
PURPOSE. The present study aimed to investigate the relationships between the crown form of the upper central incisor and their labial inclination, overbite, and overjet. MATERIALS AND METHODS. Maxillary and mandibular casts of 169 healthy dentitions were subjected to 3D dental scanning, and analyzed using CAD software. The crown forms were divided into tapered, square, and ovoid based on the mesiodistal dimensions at $20 \%$ of the crown height to that at $40 \%$. The degree of labial inclination of the upper central incisor was defined as the angle between the occlusal plane and the line connecting the incisal edge and tooth cervix. The incisal edges of the right upper and lower central incisor that in contact with lines parallel to the occlusal plane were used to determine the overbite and overjet. One-way ANOVA was performed to compare the labial inclination, overbite, and overjet among the crown forms. RESULTS. The crown forms were classified into three types; crown forms with a $20 \% / 40 \%$ dimension ratio of $1.00 \pm 0.01$ were defined as square, $>1.01$ as tapered, and $<0.99$ as ovoid. The labial inclination degree was the greatest in tapered and the least in square. Both overbite and overjet in tapered and ovoid were higher than those in square. CONCLUSION. Upper central incisor crown forms were related to their labial inclination, overbite, and overjet. It was suggested that the labial inclination, overbite, and overjet should be taken into consideration for the prosthetic treatment or restoring the front teeth crowns. [J Adv

Prosthodont 2020;12:338-43]
\end{abstract}

KEYWORDS: Upper central incisor; Crown forms; Labial inclination; Overbite; Overjet

\section{INTRODUCTION}

Esthetic demand has been on the rise in dentistry over the recent years. The crown form, degree of labial inclination of the crown axes, overbite, and overjet of the upper central incisors are particularly critical elements in prosthetic treatment aiming to achieve aesthetical and natural appear-

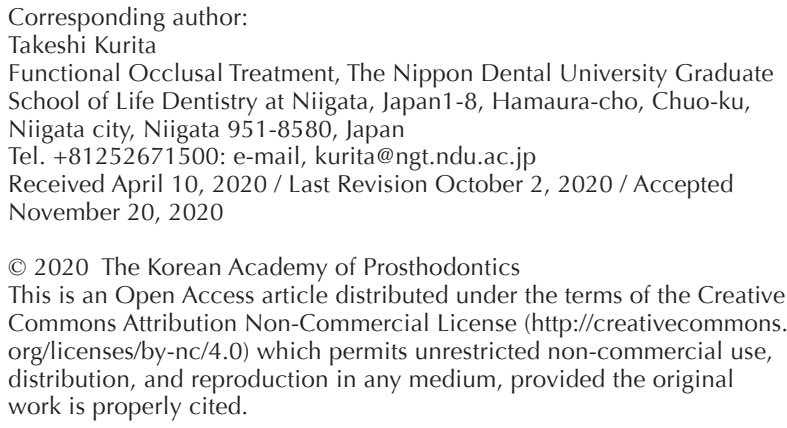

ances with harmonious stomatognathic system.

Williams ${ }^{1}$ proposed the classification of the crown forms into three types (tapered, square, and ovoid) and suggested the existence of a relationship between the crown forms and the skull shape, and between the crown forms and the facial contours. Since then, various types of classifications have been reported. ${ }^{2}$ The three basic types of the crown forms suggested by Williams have been studied, particularly in relation to the facial contours. However, the relationship between the crown forms of the upper central incisor and the facial contour has been contested by several studies. $^{2-6}$ Therefore, the significance of the three basic crown forms remains inconclusive.

The crown form of the upper central incisor is an influential factor in prosthetic treatment. The shape of the central incisor is important in clinical practice, and it is possible to design a treatment plan that takes aesthetic preference into consideration when examining the aesthetic value of dentistry. ${ }^{7-15}$ When selecting and arranging the front artificial 
teeth during prosthetic treatment or restoring the front teeth crowns, the crown form-specific characteristics need to be taken into consideration such that aesthetically pleasing and naturally appearing dentition is effectively restored. The crown form of the upper central incisor needs to consider symmetry, visual, and balance. ${ }^{9-12}$ In addition, the norms for these may differ in different populations, and thus the race should also be taken into account as a variable. There are abundant non-Japanese data regarding the factors contributing, ${ }^{16}$ but there is an insufficient data regarding these aesthetic norms among Japanese. The esthetic approach has been performed just by the fundamental esthetic criteria of an individual. Objective criteria of aesthetic approach should be established, including variations in crown form, arrangement, positioning, and relative crown lengths and lip support.

The relationships between the crown forms and overlaps are conventionally evaluated by dissecting dental casts to obtain tracings or pictures of the tooth contours on which several measurements are made. ${ }^{6}$ However, using such methods, adequate precision and objective evaluation have not been achieved. Recently, 3D geometric morphometric analysis started out to be used for the analysis of the crown length and root shape. ${ }^{17,18}$ The present study aimed to investigate the relationship between crown forms and the following features: degree of labial inclination of the tooth, overbite, and overjet using CAD software.

\section{MATERIALS AND METHODS}

The characteristics of the square shaped upper central incisors were investigated at first to obtain objective criteria for classifying crown forms because the square form is straight and easy to assess. Four dentists were asked to choose 13 casts with square-shaped upper central incisors from 50 casts ( 29 men, 21 women; mean age $22.7 \pm 3.6$ years) according to the objective criteria of Williams of the crown forms into three types. ${ }^{19,20}$ The square morphology is the most straight line, the tapered morphology has the most convergent line, and the ovoid morphology has the circular element. ${ }^{1}$ The square type is an intermediate form between the tapered type and the ovoid type. The ten casts that were identified as square by all four dentists were classified as square type. Since the characteristics of crown forms are most apparent at approximately $20-40 \%$ crown height, the mesiodistal dimensions at $20 \%$ and $40 \%$ were measured. The mean ratio with 2 SD of the dimensions at $20 \%$ of the crown height to that at $40 \%$ of the crown height (hereinafter referred to as the $20 \% / 40 \%$ dimension ratio) was calculated to define the crown forms into three types (tapered, square and ovoid). The mean ratio of $20 \% / 40 \%$ dimension ratio and the $2 \mathrm{SD}$ of square form was 1.00153 and 0.01146 , respectively. Therefore, the present study defined the crown form with a $20 \% / 40 \%$ dimension ratio of $1.00 \pm$ 0.01 as square type. A $20 \% / 40 \%$ dimension ratio $>1.01$ was defined as tapered type because the tapered type exhibits an increase in the mesiodistal dimension at the incisal edge. A $20 \% / 40 \%$ dimension ratio $<0.99$ was defined as the ovoid type, because the ovoid type exhibits a decrease in mesiodistal dimension at the incisal edge (Fig. 1).

Ratios of the dimensions at $20 \%$ of the crown height (red line) to those at $40 \%$ of the crown height (red line) were calculated to classify the crown forms into three types.

The maxillary and mandibular impressions of 169 healthy individuals ( 82 men, 87 women; mean age $21.7 \pm$ 2.8 years) with a first molar class I relationship and no malocclusions (loss of teeth, agenesis, supernumerary, maxillary protrusion, reverse articulation, edge-to-edge bite, open
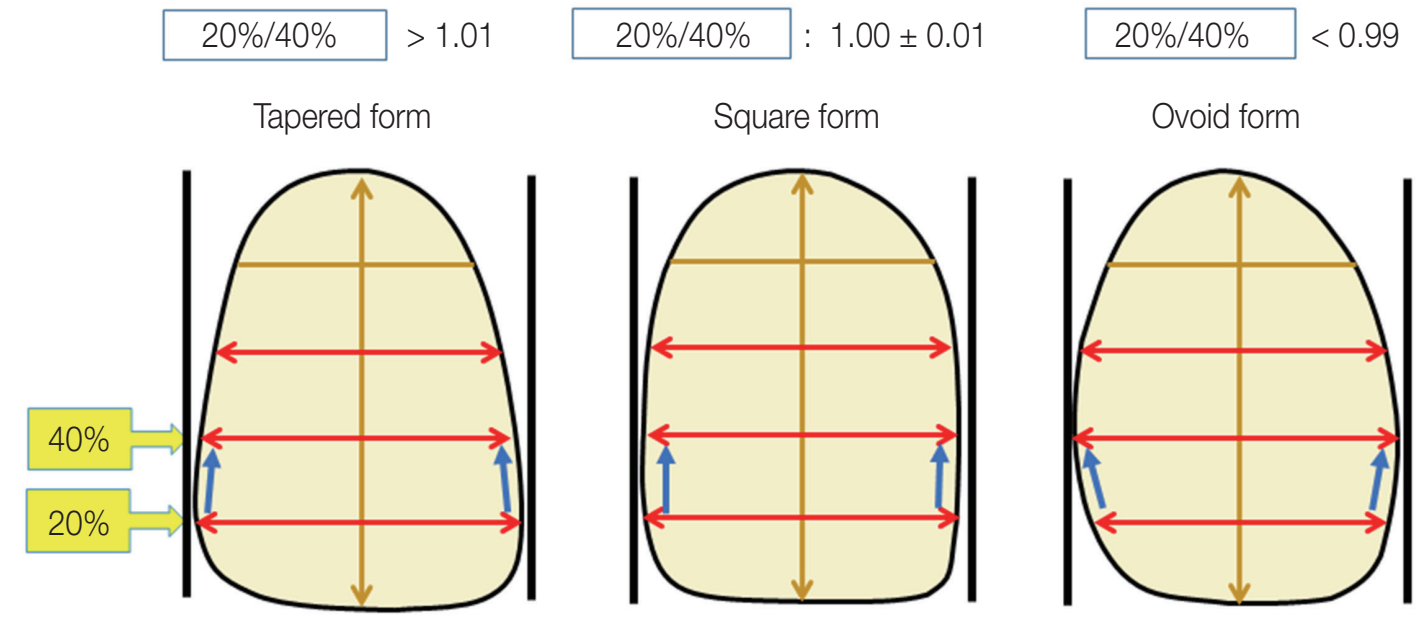

Fig. 1. Standards for classifying the crown forms into three types.

Ratios of the dimensions at $20 \%$ of the crown height (red line) to those at $40 \%$ of the crown height (red line) were calculated to classify the crown forms into three types. 
bite, deep bite, labioversion, linguoversion, and midline diastemas) and no previous history of either orthodontic treatment or crown restoration of the upper front teeth were taken to prepare dental plaster. ${ }^{21}$ Power analysis was performed, and a sample size of 159 was required to achieve a power of 0.8 and a $P=.05$ to detect the three crown forms. The present study was approved by the Ethics Committee of The Nippon Dental University School of Life Dentistry at Niigata (approval no. ECNG-H-227), and was conducted after obtaining participants' informed consent. The maxillary and mandibular casts were individually scanned ${ }^{22-25}$ using a 3D scanner (D800; 3Shape, Copenhagen, Denmark) and each set of the maxillary and mandibular casts in the intercuspal position was similarly scanned to generate threedimensional data in the position. Using CAD software (3Shape Dental System; 3Shape), the occlusal plane containing the distobuccal cusps of the lower second molars and the midpoint between the lower central incisors ${ }^{25}$ was set as the reference plane. Data acquired using CAD software was transferred to image analysis software (Adobe Photoshop CC; Adobe Inc., San Jose, CA, USA) for evaluation. The present study selected the right upper central incisor for evaluation of the crown form types. On each image of the right upper central incisor, the perpendicular distance from the incisal edge to the tooth cervix (hereinafter referred to

Table 1. Crown forms and degree of labial inclination of crown, overbite, and overjet between sexes

\begin{tabular}{|c|c|c|c|}
\hline & Males & Females & $P$ value \\
\hline \multicolumn{4}{|l|}{ Numbers of subject } \\
\hline Tapered form & 33 & 33 & \\
\hline Square form & 32 & 30 & \\
\hline Ovoid form & 17 & 24 & \\
\hline \multicolumn{4}{|l|}{ Tapered form } \\
\hline $\begin{array}{l}\text { Degree of labial inclination of } \\
\text { crown }\left(^{\circ}\right)\end{array}$ & 103.19 & 102.45 & 0.60 \\
\hline Overjet (mm) & 3.02 & 3.19 & 0.42 \\
\hline Overbite (mm) & 1.74 & 1.83 & 0.63 \\
\hline \multicolumn{4}{|l|}{ Square form } \\
\hline $\begin{array}{l}\text { Degree of labial inclination of } \\
\text { crown }\left(^{\circ}\right)\end{array}$ & 95.93 & 96.05 & 0.95 \\
\hline Overjet (mm) & 2.11 & 2.34 & 0.27 \\
\hline Overbite (mm) & 1.35 & 1.30 & 0.81 \\
\hline \multicolumn{4}{|l|}{ Ovoid form } \\
\hline $\begin{array}{l}\text { Degree of labial inclination of } \\
\text { crown }\left({ }^{\circ}\right)\end{array}$ & 99.20 & 101.75 & 0.06 \\
\hline Overjet (mm) & 2.87 & 3.10 & 0.26 \\
\hline Overbite (mm) & 1.79 & 1.75 & 0.86 \\
\hline
\end{tabular}

as the crown height) was divided into five equal parts and used for the evaluations. The mesiodistal dimensions at $20 \%, 40 \%$, and $60 \%$ of the crown height were measured to examine the features of crown form. The $20 \% / 40 \%$ dimension ratio, the $20 \% / 60 \%$ dimension ratio, and the $40 \% / 60 \%$ dimension ratio were calculated. According to the $20 \%$ / $40 \%$ dimension ratio, the casts of 169 individuals were classified into the three types. Namely, measurements of the right upper central incisors yielded a mean 20\%/40\% dimension ratio of $1.00 \pm 0.01$, which was used as a criterion for the square type. Consequently, crowns with a $20 \% / 40 \%$ dimension ratio $>1.01$ were defined as the tapered type and crowns with a $20 \% / 40 \%$ dimension ratio $<0.99$ were defined as the ovoid type. The numbers of tapered, square, and ovoid types were 66, 41, and 62, respectively. Based on the results of statistical analyses comparing the three crown forms, the 20\%/40\% dimension ratios and the $20 \% / 60 \%$ dimension ratios differed significantly among all crown forms (Table 1). The degree of labial inclination of the upper central incisor and the overbite and overjet between the upper and lower central incisors were measured on the sagittal plane passing through the midpoint of the maximum mesiodistal dimensions of the crown of the upper right incisor, and perpendicular to the occlusal plane. The degree of labial inclination of the upper central incisor was defined as the angle between the occlusal plane and the line connecting the incisal edge and the tooth cervix. ${ }^{26}$ The incisal edges of the right upper central incisor and the right lower central incisor were defined as the lowest and the highest points, respectively, that were in contact with lines parallel to the occlusal plane, and the degrees of overbite and overjet were evaluated (Fig. 2).

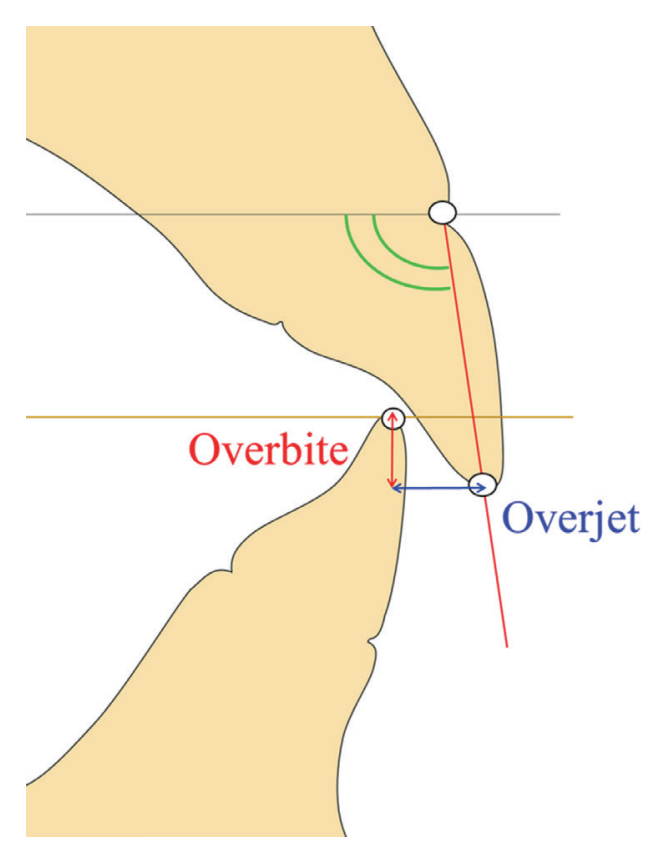

Fig. 2. Measurement of the degree of labial inclination, overbite, and overjet. 
The angle (green) between the plane parallel to the occlusal plane (black) and the line connecting the incisal edge and the tooth cervix (red) was measured as labial inclination angle. The distances between the incisal edges of the upper central incisor and the lower central incisor were measured as overbite and overjet. The yellow line runs parallel to the occlusal plane.

Statistical software (Excel statistics 2015, SSRI, Tokyo, Japan) was used for the analysis. A one-way analysis of variance was also performed to compare the degree of labial inclination of the upper central incisor and the degrees of overbite and overjet among the three types of the crown forms. In addition, the significant factors identified were further tested using Tukey-Kramer multiple comparison analysis.

\section{RESULTS}

The degree of labial inclination differed significantly between the tapered type and the square type $(P<.01)$, between the square type and the ovoid type $(P<.01)$, and between the tapered type and the ovoid type $(P<.05)$ (Fig. $3)$. The degrees of inclinations were the greatest in the tapered type, followed by the ovoid and then the square type. The degree of overbite varied significantly between the tapered type and the square type, and between the square type and the ovoid type $(P<.05)$. In addition, the tapered type and the ovoid type had higher degrees of overbite than the square type (Fig. 4). The degree of overjet also differed significantly between the tapered type and the square type, and between the square type and the ovoid type $(P<.01)$. The tapered type and the ovoid type had higher degrees of overjet than the square type (Fig. 5).

\section{DISCUSSION}

This study investigated the relationship between crown forms and the following features: degree of labial inclination of the tooth, overbite, and overjet using CAD software. Unlike conventional methods, using a 3D scanner does not require the physical dissection of casts. Instead, digitalized 3D data could be used to obtain accurate measurements from cross-sectional images of the crowns even at the intercuspal position. Therefore, use of digitalized 3D data is effective for the classification of crown forms and the investigation of the degree of labial inclination of the tooth, overbite, and overjet.

The present study measured the degree of labial inclination of the tooth, the degree of the overbite, and overjet on sagittal plane images generated from 3D scanned data and did not involve the dissection of casts, which resulted in high precision and objectivity. In addition, the distance from the incisal edge of the upper central incisor to that of the lower central incisor, not to the labial surface of the lower central incisor, could be regarded as the degree of overjet. There is a positive correlation between the degree of overbite and the thickness of an incisor. ${ }^{27}$ However, the influ-

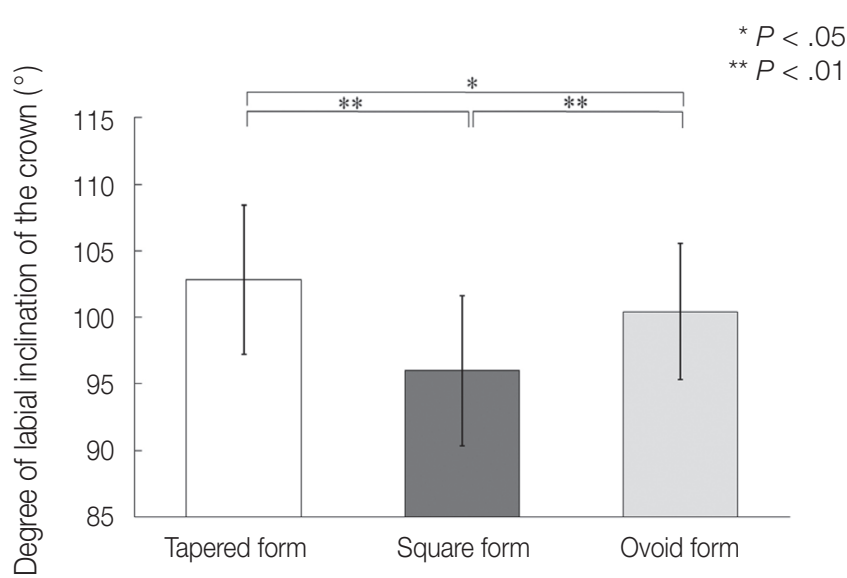

Fig. 3. Degree of labial inclination of the crown. Means and SD values are shown.

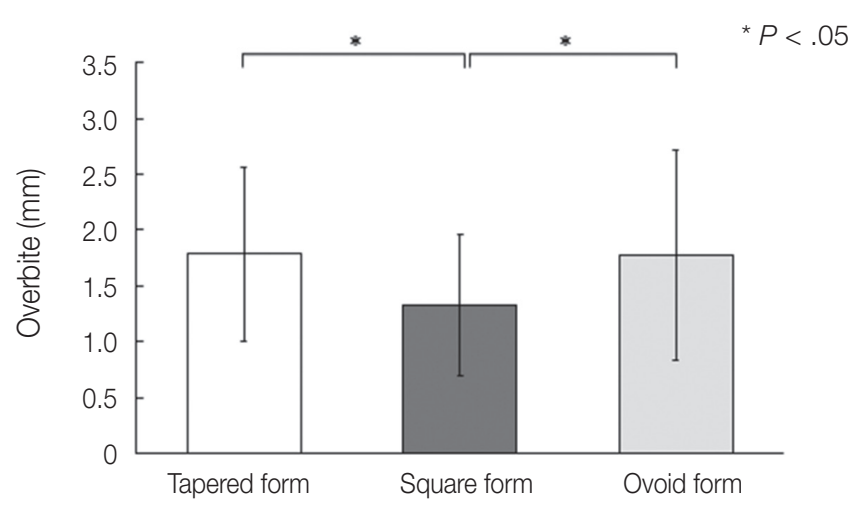

Fig. 4. Overbite. Means and SD values are shown.

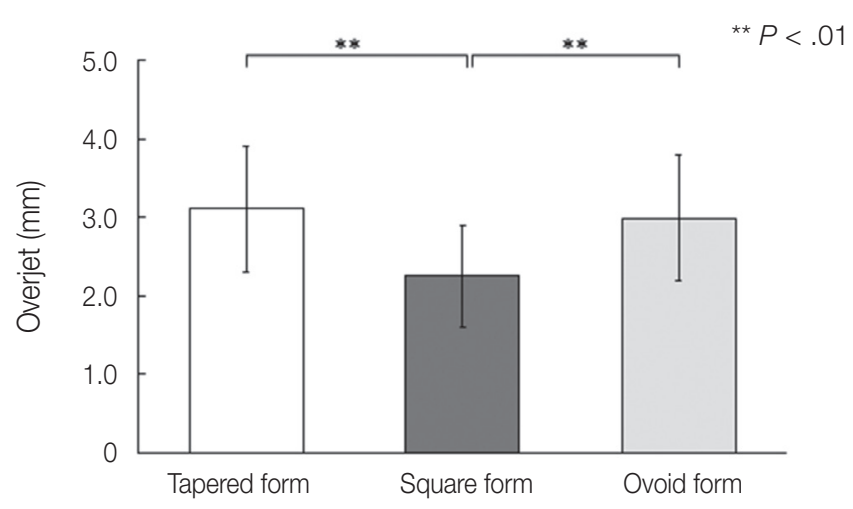

Fig. 5. Overjet. Means and SD values are shown. 
ence of incisor thickness, maxillary lingual surface, and mandibular labial surface were potentially negligible in the present study because the incisor edges of the upper and lower central incisors were used as reference points for the degrees of the overbite and overjet.

The tapered type exhibited the greatest degree of the labial inclination of the tooth, followed by the ovoid type and then the square type. The result could be due to differences in the gaps between the mesiodistal dimensions of the tooth cervix and the maximum mesiodistal dimensions of the crown of the upper right central incisor. In tapered type crowns, the mesiodistal dimensions at $60 \%$ of the crown height were relatively small and increased in size with increase in proximity to the incisal edge. In addition, the mesiodistal dimensions at $60 \%$ of the crown height were relatively small and were larger at $40 \%$ the crown height in the ovoid type. Consequently, the dentition could be achieved by inclining the labial surface of the crown towards the labial direction in the tapered and ovoid crowns. Conversely, the gaps among the mesiodistal dimension at $60 \%, 40 \%$, and $20 \%$ of the crown height were relatively small and the crown shapes were parallel in the square type. Consequently, the labial surfaces of the central incisors would not incline towards the labial direction in the square crowns. The finding suggests that the use of the tapered or the ovoid crown forms is desirable when the lip support is strong during the determination of the maxilla-mandibular relationships in removable dentures, and the square crown form is preferable when the lip support is weak.

The tapered and the ovoid crown types, but not the square type, had high degrees of the overbite and overjet. The crown lengths of the upper incisors are longer than those of the lower incisors. Consequently, incisal edges of the upper incisors were positioned in the anterior direction with increase in the degree of labial inclination. An increase in the degree of labial inclination also resulted in an increase in the degrees of the overbite and overjet. Namely, the degrees of overbite and overjet increased in the tapered and ovoid types that had high degrees of labial inclination in comparison with the square type, which exhibited smaller degrees of labial inclination. Therefore, large degrees of overbite and overjet are desirable with the tapered or ovoid forms, while minimal degrees of the overbite and overjet are preferable when using the square forms during crown restoration.

The shape of the maxillary central incisor is visually most important when planning treatment for aesthetic cases in the clinic, ${ }^{7-16}$ and there is a relationship between the crown morphology of the upper central incisors and the pleasant appearance of smiles and smiling images. ${ }^{7-9}$ Concerning the labial inclination, Praveen Chirivella et al..$^{12}$ emphasized maxillary incisor labiolingual inclination and anteroposterior position to influence smiling profile esthetics. There is a relationship between the shape of the upper central incisor and the crown axis, and it may contribute to the determination of the aesthetic vertical position. ${ }^{28}$ The results of this study showed that the labial inclination dif- fers depending on the crown form. Concerning the overjet and overbite, the vertical position of central incisor and the incisal edge has a significant influence on the aesthetics of the positional relationship. ${ }^{10,11,15}$ The average value of the overbite is reported as $2.9 \mathrm{~mm}$ and that of the overjet is 2.4 $\mathrm{mm}$ in Chinese. ${ }^{14}$ In German, the average value of the overbite is reported as $3.2 \mathrm{~mm}$, and that of the overjet as 3.1 $\mathrm{mm} .{ }^{9}$ In this study, the average value of the overbite was $1.95 \mathrm{~mm}$, and that of the overjet was $3.1 \mathrm{~mm}$ in Japanese. The overjet was similar to the previous study, ${ }^{9}$ but the value of the overbite was different from the previous study. From these results, it was considered that the overbite could be different among the race.

The crown form, degree of labial inclination, overbite, and overjet of the upper central incisors are particularly critical elements in prosthetic treatment aiming to achieve aesthetical and natural appearances with harmonious stomatognathic system. The incisor overbite and overjet are associated with esthetic impairments of oral health-related quality of life. ${ }^{9}$ The results of this study made it clear that the crown form had relation to the labial inclination, overbite, and overjet.

\section{CONCLUSION}

The conclusion of this study suggested that when selecting and arranging the front artificial teeth during prosthetic treatment or restoring the front teeth crowns, the crown form-specific characteristics (e.g., the labial inclination degree and the degrees of overbite and overjet) need to be taken into consideration as opposed to maintaining the use of conventional uniform standards when seeking to achieve and restore aesthetically pleasant and naturally appearing dentitions.

\section{ACKNOWLEDGMENTS}

We sincerely thank Professor Yukio Miyagawa for his supervision, especially for the statistical analysis.

\section{ORCID}

Takeshi Kurita bttps://orcid.org/0000-0001-7008-9846

Fumi Mizuhashi https://orcid.org/0000-0002-0699-0637

Toshihide Sato https://orcid.org/0000-0002-7563-6316

Kaoru Koide https://orcid.org/0000-0003-0935-1045

\section{REFERENCES}

1. Williams JL. A new classification of human tooth forms with a special reference to a new system of artificial teeth. 1st ed. New York, NY: The Dentisti Supply Co.; 1914. p. 30-7.

2. Ibrahimagić L, Jerolimov V, Celebić A, Carek V, Baucić I, Zlataric DK. Relationship between the face and the tooth form. Coll Antropol 2001;25:619-26.

3. Wolfart S, Menzel H, Kern M. Inability to relate tooth forms to face shape and gender. Eur J Oral Sci 2004;112:471-6. 
4. Silva FAP, Almeida NLF, Ferreira DF, Mesquita MF, Negreiros WA. Digitized study of the correlation between the face and tooth shapes in young adult individuals. Braz J Oral Sci 2007;6:1383-6.

5. de Oliveira Farias F, Ennes JP, Zorzatto JR. Aesthetic value of the relationship between the shapes of the face and permanent upper central incisor. Int J Dent 2010;2010:561957.

6. Mehndiratta A, Bembalagi M, Patil R. Evaluating the aAssociation of tooth form of maxillary central incisors with face shape using autoCAD software: A descriptive study. J Prosthodont 2019;28:e469-72.

7. Anderson KM, Behrents RG, McKinney T, Buschang PH. Tooth shape preferences in an esthetic smile. Am J Orthod Dentofacial Orthop 2005;128:458-65.

8. Pedrosa VO, França FM, Flório FM, Basting RT. Study of the morpho-dimensional relationship between the maxillary central incisors and the face. Braz Oral Res 2011;25:210-6.

9. Sierwald I, John MT, Schierz O, Jost-Brinkmann PG, Reissmann DR. Association of overjet and overbite with esthetic impairments of oral health-related quality of life. J Orofac Orthop 2015;76:405-20.

10. Betrine Ribeiro J, Alecrim Figueiredo B, Wilson Machado A. Does the presence of unilateral maxillary incisor edge asymmetries influence the perception of smile esthetics? J Esthet Restor Dent 2017;29:291-7.

11. Menezes EBC, Bittencourt MAV, Machado AW. Do different vertical positions of maxillary central incisors influence smile esthetics perception? Dent Press J Orthod 2017;22:95-105.

12. Chirivella P, Singaraju GS, Mandava P, Reddy VK, Neravati JK, George SA. Comparison of the effect of labiolingual inclination and anteroposterior position of maxillary incisors on esthetic profile in three different facial patterns. J Orthod Sci 2017;6:1-10.

13. Magne P, Salem P, Magne M. Influence of symmetry and balance on visual perception of a white female smile. J Prosthet Dent 2018;120:573-82.

14. Liu R, Hu A, Niu L, Wang F, Lu Y, Zhou Q. Association of incisal overlaps with /s/ sound and mandibular speech movement characteristics. Am J Orthod Dentofacial Orthop 2019;155:851-9.

15. Simões D, Meyge de Brito G, Teixeira Cangussu MC. Does the vertical position of maxillary central incisors in men influence smile esthetics perception? Am J Orthod Dentofacial Orthop 2019;156:485-92.

16. Álvarez-Álvarez L, Orozco-Varo A, Arroyo-Cruz G, JiménezCastellanos E. Width/length ratio in maxillary anterior teeth. Comparative study of esthetic preferences among professionals and laypersons. J Prosthodont 2019;28:416-20.

17. Singleton M, Rosenberger AL, Robinson C, O'neill R. Allometric and metameric shape variation in pan mandibular molars: A digital morphometric analysis. The Anatomical Record 2011;294:322-34.

18. Le Cabec A, Gunz P, Kupczik K, Braga J, Hublin JJ. Anterior tooth root morphology and size in Neanderthals: Taxonomic and functional implications. J Human Evolution 2013;64:16993.

19. Chou YH, Tsai CC, Wang JC, Ho YP, Ho KY, Tseng CC.
New classification of crown forms and gingival characteristics in taiwanese. Open Dent J 2008;2:114-9.

20. Song JW, Leesungbok R, Park SJ, Chang SH, Ahn SJ, Lee SW. Analysis of crown size and morphology, and gingival shape in the maxillary anterior dentition in Korean young adults. J Adv Prosthodont 2017;9:315-20.

21. Susami R, Asai Y, Hirose K, Hosoi T, Hayashi I, Takimoto T. The prevalence of malocclusion in Japanese school children. 1. Total frequency. J Jap Orthod Soc 1971;30:221-9. (in Japanese)

22. Dai N, Hu J, Liu H. 3D Simulation modeling of the tooth wear process. PLoS One 2015;10:e0134807.

23. Lee WS, Park JK, Kim JH, Kim HY, Kim WC, Yu CH. New approach to accuracy verification of 3D surface models: An analysis of point cloud coordinates. J Prosthodont Res 2016; 2:98-105.

24. Renne W, Ludlow M, Fryml J, Schurch Z, Mennito A, Kessler $\mathrm{R}$, Lauer A. Evaluation of the accuracy of 7 digital scanners: An in vitro analysis based on 3-dimensional comparisons. J Prosthet Dent 2017;118:36-42.

25. Oxilia G, Bortolini E, Martini S, Papini A, Boggioni M, Buti L, Figus C, Sorrentino R, Townsend G, Kaidonis J, Fiorenza L, Cristiani E, Kullmer O, Moggi-Cecchi J, Benazzi S. The physiological linkage between molar inclination and dental macrowear pattern. Am J Phys Anthropol 2018;166:941-51.

26. Fujikawa Y. Study on angle of inclination and rotation of tooth crown in natural dental arch. J Stomatological Soc 1958; 25:475-94. (in Japanese)

27. Chu SJ, Tarnow DP, Tan JH, Stappert CF. Papilla proportions in the maxillary anterior dentition. Int J Periodontics Restorative Dent 2009;29:385-93.

28. Naini FB, Manouchehri S, Al-Bitar ZB, Gill DS, Garagiola U, Wertheim D. The maxillary incisor labial face tangent: clinical evaluation of maxillary incisor inclination in profile smiling view and idealized aesthetics. Maxillofac Plast Reconstr Surg 2019;41:31. 